\title{
BMJ Open Can delirium research activity impact on routine delirium recognition? A prospective cohort study
}

\author{
Carly Welch, Thomas A Jackson
}

To cite: Welch C, Jackson TA. Can delirium research activity impact on routine delirium recognition? A prospective cohort study. BMJ Open 2018;8:e023386. doi:10.1136/ bmjopen-2018-023386

- Prepublication history for this paper is available online. To view these files please visit the journal online (http://dx.doi. org/10.1136/bmjopen-2018023386).

Received 5 April 2018

Revised 11 July 2018

Accepted 20 September 2018

Check for updates

(C) Author(s) (or their employer(s)) 2018. Re-use permitted under CC BY-NC. No commercial re-use. See rights and permissions. Published by BMJ.

Institute of Inflammation and Ageing, College of Medical and Dental Sciences, University of Birmingham, Birmingham, UK

Correspondence to

Dr Carly Welch;

cxw626@bham.ac.uk

\section{ABSTRACT}

Objective To assess if ongoing delirium research activity within an acute admissions unit impacts on prevalent delirium recognition.

Design Prospective cohort study.

Setting Single-site tertiary university teaching hospital. Participants 125 patients with delirium, as diagnosed by an expert using Diagnostic and Statistical Manual of Mental Disorders, Fourth Edition reference criteria, were recruited to a prospective cohort study investigating use of informant tools to detect unrecognised dementia. This study evaluated recognition of delirium and documentation of delirium by medical staff.

Interventions The main study followed an observational design; the intervention discussed was the implementation of this study itself.

Primary and secondary outcome measures The primary outcome was recognition of delirium by the admitting medical team prior to study diagnosis.

Secondary outcomes included recording of or description of delirium in discharge summaries, and factors which may be associated with unrecognised delirium.

Results Delirium recognition improved between the first half $(48 \%)$ and second half $(71 \%)$ of recruitment $(p=0.01)$. There was no difference in recording of delirium or description of delirium in the text of discharge summaries. Conclusion Delirium research activity can improve recognition of delirium. This has the potential to improve patient outcomes.

\section{BACKGROUND}

Hospitals with high clinical research activity have better patient outcomes. ${ }^{1-4}$ Reasons for this association remain undetermined. The effect remains after adjustment for staffing, radiology service provision, operating theatres and critical care beds. ${ }^{1}$ Patient outcomes might be improved by locally increased clinical knowledge extrapolated from ongoing research projects or through increased morale among clinical staff involved in research. ${ }^{1-4}$ Research that aims to decipher the reasons for associations between research activity and patient outcomes is vital as findings can be used to improve patient outcomes in hospitals with less clinical research activity.

\section{Strengths and limitations of this study}

This is the first study to demonstrate the impact of delirium research activity on delirium recognition.

- Delirium was diagnosed in this study by an expert using Diagnostic and Statistical Manual of Mental Disorders, Fourth Edition reference criteria. Results, therefore, represent true delirium recognition.

- Due to the design of this study, we did not measure delirium recognition rates prior to or after recruitment to the main study. We do not know if the effect was maintained following completion of the main study.

Delirium is an acute severe neuropsychiatric syndrome. It has been defined most recently by the Diagnostic and Statistical Manual of Mental Disorders, Fifth Edition (DSM-V) as disturbance in attention, awareness and cognition, which develops over a short time period (normally hours to days), is caused by direct physiological consequences of another medical condition and is not better explained by another pre-existent neurocognitive disorder. ${ }^{5}$ Prior to this, delirium was defined by DSM-IV as a disturbance of consciousness with a change in cognition or perceptual disturbance, which develops over an acute time period, tends to fluctuate and is caused by direct physiological consequences of another medical condition. Delirium affects $20 \%$ of hospitalised adults, ${ }^{6}$ not including intensive care unit (ICU) admissions; prevalence within ICU rises to $80 \% .^{7}$ Delirium prevalence also increases with age. ${ }^{8}$ Delirium may be present on admission (prevalent delirium) or may develop during hospital admission (incident delirium), and may present as hyperactive, mixed or hypoactive subtypes. ${ }^{9}$ However, delirium remains under-recognised in practice. ${ }^{610-13}$

Delirium is an independent risk factor for increased 6-month mortality following hospitalisation of older adults. ${ }^{14}$ Particularly, unrecognised delirium, delayed delirium 
treatment and increased delirium duration are associated with increased mortality. ${ }^{13}{ }^{15-17}$ Delirium recognition ensures careful evaluation of precipitating factors and implementation of prevention strategies to avoid worsening of delirium. ${ }^{8} 18$ Recognition can thus assist to shorten delirium duration and improve mortality and other outcomes. ${ }^{19}$ Delirium has been shown to be under-recognised in $30 \%-75 \%$ of patients, ${ }^{6}{ }^{10-13}$ and is also under-reported in the National Health Service. ${ }^{20}$ Previous research has shown that delirium recognition can be improved through educational interventions. ${ }^{21}{ }^{22}$ In addition, within the UK, it is recommended by the National Institute of Health and Care Excellence (NICE) that any diagnosis of delirium made during a hospital admission be clearly communicated to their general practitioner $(\mathrm{GP})^{23}$; this is important for follow-up and evaluation of underlying undiagnosed cognitive impairment. ${ }^{24}$ Identifying methods to improve delirium recognition and documentation can assist to improve patient outcomes.

\section{METHODS}

\section{Objective}

This study aimed to assess if ongoing delirium research activity within an acute admissions unit could impact on prevalent delirium recognition. We also aimed to explore factors which may be associated with unrecognised delirium.

\section{Study design and setting}

The study design for the main study has been described elsewhere. ${ }^{24}$ Briefly, patients aged 70 and older were screened for evidence of delirium within 24 hours of admission to the acute medical admissions unit at Queen Elizabeth Hospital Birmingham. Delirium was diagnosed using DSM-IV reference criteria by an expert consultant geriatrician (TAJ). Patients with delirium were recruited to a prospective cohort study investigating use of informant tools to detect unrecognised dementia. Acute Mental Test Score, digit span score and presence or absence of delirium were recorded in the medical notes of all screened patients. These findings were recorded regardless of whether or not they were recruited to the main study. Screening for delirium for the purposes of this study took place only after the patient had been seen and assessed by the responsible medical team.

The researchers did not provide specific formal education or training about delirium diagnosis to clinicians outside of the research team. However, TAJ would frequently converse with clinicians working within the medical admissions unit who enquired about the research study and explain about the importance of recognising delirium. The results of delirium screening were very easily accessible to the clinical team, and where delirium was present, this was clearly documented with advice for the clinical team to consider. Screening for delirium occurred between 09:00 and 17:00 each day and occurred alongside post-take ward rounds.

\section{Data extraction}

Delirium recognition was defined as a written diagnosis of delirium documented in the patient care record by the usual care team during the first 24 hours of admission, prior to screening for study purposes. Healthcare staff outside of the research team were unaware that delirium recognition was being assessed or recorded. Delirium motor subtype and dementia status, defined as an Informant Questionnaire on Cognitive Decline in the ElderlyShort Version score greater than 3.82, ${ }^{24}$ were recorded. Following discharge, formal discharge letters (which communicated the admission details and diagnosis to the GP) were examined for documentation of delirium as a discharge diagnosis. Text was examined for description of delirium using informal terms. In cases where patients died during admission, the medical certificate of cause of death and letter to GP were examined. Analysis of discharge summaries was completed by a single researcher (CW) who was unaware if delirium had been recognised on admission.

\section{Statistical analysis}

Admissions were divided temporally into categorical halves and quartiles of consecutive recruitment for analysis (ie, first half recruited and second half recruited; first, second, third and fourth quartiles recruited). Due to an odd total number, the additional participant was randomly allocated to the first half and the final quartile. Significance of differences in delirium recognition across groups were examined using Fisher's exact test and $\chi^{2}$ tests as appropriate using IBM SPSS Statistics 22. Data were examined with respect to differences between age, gender, delirium motor subtype, dementia status, length of stay (LOS) and mortality between groups and between recognised and unrecognised delirium. Significance of differences in LOS and mortality was determined using Kruskal-Wallis tests. If any significant differences were found between those recognised and unrecognised, we planned to conduct logistic regression models to identify factors that predicted unrecognised delirium.

\section{Patient involvement}

The James Lind Alliance published priority setting partnerships related to dementia in 2013, which informed further work led by the Alzheimer's Society. It was identified that some of the most important priorities to patients and carers of individuals with dementia were the impact of early diagnosis, caring for people with dementia during acute hospital admissions and how to effectively implement research findings into practice. ${ }^{25}$ Locally, a pilot study of nine individuals was undertaken prior to the initial study, which demonstrated that patients and their consultees (non-statutorily defined personal representatives who knew the patient well and who could consider their past wishes) found the assessments acceptable. Written consultee declaration was obtained from personal consultees for research participation where patients were deemed to lack capacity to consent. The results of the 
Table 1 Comparison of results and patient demographics by halves

\begin{tabular}{|c|c|c|c|c|c|c|c|c|}
\hline & & All & $\begin{array}{l}\text { First half } \\
n=63\end{array}$ & $\begin{array}{l}\text { Second half } \\
n=62\end{array}$ & $P$ values & $\begin{array}{l}\text { Recognised } \\
\mathrm{n}=74\end{array}$ & $\begin{array}{l}\text { Unrecognised } \\
n=51\end{array}$ & $P$ values \\
\hline Age & Mean (SD) & 84.4 & 83.78 & 85.03 & 0.18 & $85(5.8)$ & $84(7.4)$ & 0.65 \\
\hline Gender & Male & 47 (38\%) & 27 (43\%) & $20(32 \%)$ & 0.27 & 27 (36\%) & $20(39 \%)$ & 0.85 \\
\hline \multirow[t]{3}{*}{ Subtype } & Hyperactive & 37 (29\%) & 18 (29\%) & 19 (31\%) & 0.96 & 25 (34\%) & $12(23 \%)$ & \\
\hline & Hypoactive & 67 (54\%) & 34 (54\%) & $33(53 \%)$ & & 35 (47\%) & $32(63 \%)$ & 0.23 \\
\hline & Mixed & $21(17 \%)$ & $11(17 \%)$ & $10(16 \%)$ & & $14(19 \%)$ & 7 (14\%) & \\
\hline \multicolumn{2}{|c|}{ IQCODE >3.82 } & 71 (57\%) & $36(57 \%)$ & 35 (56\%) & 0.77 & $31(42 \%)$ & $15(29 \%)$ & 0.97 \\
\hline \multicolumn{2}{|c|}{ Inpatient mortality } & $12(10 \%)$ & $5(8 \%)$ & $7(11 \%)$ & 0.73 & $8(11 \%)$ & $4(8 \%)$ & 0.76 \\
\hline \multicolumn{2}{|c|}{ Delirium recognised } & 74 (59\%) & 30 (48\%) & $44(71 \%)$ & 0.01 & NA & NA & NA \\
\hline \multicolumn{2}{|c|}{$\begin{array}{l}\text { Delirium as discharge } \\
\text { diagnosis }\end{array}$} & $61(49 \%)$ & $26(41 \%)$ & $35(56 \%)$ & 0.11 & NA & NA & NA \\
\hline \multicolumn{2}{|c|}{$\begin{array}{l}\text { Delirium described on } \\
\text { discharge }\end{array}$} & $62(50 \%)$ & 33 (52\%) & $29(47 \%)$ & 0.59 & NA & NA & NA \\
\hline & & All & $\begin{array}{l}\text { First half } \\
n=57\end{array}$ & $\begin{array}{l}\text { Second half } \\
n=56\end{array}$ & $P$ values & $\begin{array}{l}\text { Recognised } \\
\mathrm{n}=66\end{array}$ & $\begin{array}{l}\text { Unrecognised } \\
\mathrm{n}=47\end{array}$ & $P$ values \\
\hline \multicolumn{2}{|c|}{ Median LOS (days) } & 16 & 17 & 13.5 & 0.43 & 17 & 13.5 & 0.18 \\
\hline & & All & $\begin{array}{l}\text { First half } \\
\mathrm{n}=54\end{array}$ & $\begin{array}{l}\text { Second half } \\
n=53\end{array}$ & $P$ values & $\begin{array}{l}\text { Recognised } \\
\mathrm{n}=64\end{array}$ & $\begin{array}{l}\text { Unrecognised } \\
n=43\end{array}$ & $P$ values \\
\hline \multicolumn{2}{|c|}{ 12-month mortality } & 42 (39\%) & 24 (44\%) & 18 (34\%) & 0.27 & 26 (41\%) & 16 (37\%) & 0.72 \\
\hline
\end{tabular}

Delirium recognition improved between the first half of recruitment and the second half of recruitment. There was no difference in age, gender, delirium subtype, dementia status or mortality between halves of recruitment or between recognised and unrecognised delirium. IQCODE, Informant Questionnaire on Cognitive Decline in the Elderly; LOS, length of stay; NA, not applicable.

main study were presented at the Age Well conference in Birmingham and disseminated to study participants and their consultees.

\section{RESULTS}

Delirium was diagnosed in $228(17.2 \%)$ of 1327 patients screened for delirium. One hundred and twenty five participants were recruited between March 2013 and November 2014. Reasons for non-recruitment included lack of available consultees, risk of imminent death, inability to communicate in English, consultee declining participation or previous recruitment. This has been described elsewhere in more detail. ${ }^{24}$ Table 1 depicts demographic data, delirium subtype, dementia status and delirium recognition between groups. There was no difference in age, gender, delirium subtype, dementia status or inpatient mortality between the two halves. The date range for the first half of patients recruited was $4 / 3 / 2013-11 / 11 / 2013$ and the date range for the second half was 12/11/2013-18/11/2014. Date ranges for quartiles of admission were 4/3/2013-5/6/2013, 6/6/2013-11/11/2013, 12/11/2013-6/5/2014 and 7/5/2014-18/11/2014, respectively.

\section{Admission recognition}

Delirium was recognised in 74/125 (59\%) overall. Delirium was recognised in 30/63 $(48 \%)$ in the first half, and $44 / 62(71 \%)$ in the second half $(\mathrm{p}=0.01)$. There was no difference in age, gender, delirium subtype, dementia status or mortality between recognised or unrecognised delirium (table 1). As we did not identify any significant difference between factors, we did not proceed to perform logistic regression models. Table 2 demonstrates our results divided by quartiles. Delirium recognition improved from the first quartile when compared with the second, third and fourth quartiles $(42 \%, 52 \%, 74 \%, 69 \%$, $\mathrm{p}=0.034$ ). Motor subtype was specified on admission in

Table 2 Comparison of results by quartiles

\begin{tabular}{lcllll}
\hline & $\begin{array}{l}\text { First quartile } \\
(\mathbf{n}=\mathbf{3 1})\end{array}$ & $\begin{array}{l}\text { Second quartile } \\
(\mathbf{n}=\mathbf{3 1})\end{array}$ & $\begin{array}{l}\text { Third quartile } \\
(\mathbf{n}=\mathbf{3 1})\end{array}$ & $\begin{array}{l}\text { Fourth quartile } \\
(\mathbf{n}=\mathbf{3 2})\end{array}$ & P values \\
\hline Delirium recognised & $13(42 \%)$ & $16(52 \%)$ & $23(74 \%)$ & $22(69 \%)$ & 0.03 \\
\hline Delirium as discharge diagnosis & $9(29 \%)$ & $17(55 \%)$ & $15(48 \%)$ & $20(62 \%)$ & 0.052 \\
\hline Delirium described on discharge & $18(58 \%)$ & $14(45 \%)$ & $12(39 \%)$ & $18(56 \%)$ & 0.37 \\
\hline
\end{tabular}

Delirium recognition improved between the first quartile and the second, third and fourth quartile. There was a trend towards increased documentation of delirium as a discharge diagnosis between the first and the second, third and fourth quartiles. 
eight patients with delirium; seven of these were concordant with expert assessment at recruitment (all hypoactive). LOS was available for all 113 patients who were alive at discharge. Twelve-month mortality (including those patients who died during admission) was available for 107 patients. There was no statistically significant difference in either LOS or 12-month mortality between patients in whom delirium was recognised compared with those in whom delirium was unrecognised.

\section{Discharge documentation}

There was no difference in recording of delirium as a diagnosis, or description of delirium in discharge summaries between the first and second halves of recruitment. There was a trend towards increased documentation of delirium as a discharge diagnosis in the second, third and fourth quartiles compared with the first quartile $(29 \%, 55 \%$, $48 \%, 62 \%, \mathrm{p}=0.052)$. There was a clinical description of delirium in the discharge text of 62/113 (55\%) patients. Of these patients, confusion was described in 56/62 $(88 \%)$, drowsiness in $12 / 62(19 \%)$ and agitation in $5 / 62$ $(8 \%)$. No patients were described as being disorientated. Of the 12 in whom drowsiness was described, all except for one patient had a diagnosis of hypoactive delirium confirmed with expert assessment. Twelve patients died during admission. None of these included delirium as a diagnosis that had caused or contributed towards their death on formal death certification, or included delirium in summaries sent to the GP in relation to the admission.

\section{DISCUSSION}

Delirium recognition improved between the first half of recruitment and second half. There was no change in local hospital policy during this time period that may have affected this. Local hospital policy was concordant with British Geriatrics Society and NICE guidelines, which recommend that all patients aged 65 years and older who are newly admitted to hospital are screened for delirium. ${ }^{23}$ This guidance existed throughout the course of this research project and did not change during this time. Formal delirium diagnosis was made during the initial study using recognised DSM-IV criteria by an expert; results are representative of true delirium recognition. The protocol for this study was developed and approved prior to the introduction of DSM-V and we recognise that there are differences between DSM-IV and DSM-V. However, concordance of $91 \%$ between DSM-IV and DSM-V has been demonstrated when using a relaxed approach to the DSM-V criteria. ${ }^{26}$

Increased knowledge of delirium through awareness of ongoing recruitment to the main study may have aided to increase recognition. This demonstrates a potentially indirect means by which increased local research activity can improve patient outcomes. However, we did not identify any statistically significant difference in LOS, inpatient mortality or 12-month mortality between patients in whom delirium was recognised compared with those in whom delirium was unrecognised. This may have been due to underpowering of this study and missing data at follow-up but we acknowledge that no clear correlation between delirium recognition and LOS has been demonstrated. We did not collect data on other outcomes that may have correlated with delirium recognition such as inpatient falls, avoidance of sedative medications, reduction in anticholinergic drug burden, functional status on discharge or need for institutionalisation. Additionally, it is important to note that following delirium screening for study purposes, the presence or absence of delirium was documented in the medical notes so that intervention strategies could be put into place by the medical team. As all patients were recruited to this study within the first 24 hours of admission, this will have allowed early intervention to be put into place for all patients regardless of initial recognition by the admitting team.

Documentation of delirium in discharge summaries did not improve during this study. This may have been due to patients being discharged from clinical areas other than the acute admissions unit, and reduced awareness by discharging physicians of the main study. However, many medical staff working in discharging areas would have rotated through the acute admissions unit. Medical staff may have been unaware of the importance of documenting delirium on discharge summaries, as this was not an aspect included in the main study. To minimise potential bias, examination of discharge summaries was performed by a separate independent researcher who was not aware of the results of the admission recognition data.

Early patient and public involvement in the planning of our research project ensured that this project was of relevance to the interests of older adults and their carers. In particular, our pilot study assisted to refine the protocol for the main study and verify the acceptability of the assessments performed. Dementia remains a priority research topic for older adults and their carers. Delirium is often less well understood by patients and members of the public compared with dementia but is considered an important problem when the condition is explained to them.

Overall rates of delirium recognition compared better than previous research in other settings. The development of NICE guidelines in $2010^{23}$ and increased undergraduate teaching ${ }^{27}$ are likely to have influenced this. We did not conduct follow-up assessments following completion of this study to assess if the effect was maintained. Baseline recognition rates prior to recruitment to this study were also not measured. Due to the design of this study, we were only able to assess the impact of our study on recognition of prevalent delirium in patients included within the main study. We also did not assess the impact on recognition of incident delirium or prevalent delirium in patients not included in the main study.

We did not demonstrate a significant difference in recognition of delirium between subtypes. This is in contrast to previous research, which has demonstrated 
that hypoactive delirium is recognised less frequently than other subtypes. ${ }^{12}$ However, our study was not powered to detect a difference in recognition between subtypes. A non-significant difference of 52\% recognition among hypoactive patients compared with $67 \%$ recognition among hyperactive and mixed subtypes was observed overall.

This is the first study to show the effect of delirium research activity on delirium recognition. Our results correspond to previous studies that have demonstrated a positive effect of research activity on patient outcomes. Further research is needed to assess if similar effects are observed with research studies of alternative design. Demonstrating positive indirect benefits of research activity on patient outcomes may encourage increased engagement of hospital trusts in research. Our study demonstrates that delirium recognition can be improved through informal education and collaborative working within an acute admissions unit; a similar approach of embedding a specialist delirium or geriatric medicine team within the acute admissions unit could have a similar positive impact in clinical practice.

Contributors TAJ was responsible for recruitment of patients to this study and recording of delirium recognition. CW was responsible for review of delirium documentation on discharge summaries. TAJ and CW jointly performed the analysis and agreed on the text of the manuscript.

Funding TAJ was supported by the Research into Ageing Fund, a fund set up and managed jointly by Age UK and the British Geriatrics Society (\#367).

Disclaimer The study sponsor had no role in study design, the collection, analysis and interpretation of data, the writing of the report or in the decision to submit the paper for publication. CW is funded by a National Institute for Health Research (NIHR), UK, Academic Clinical Fellowship award. The views expressed are those of the authors and not necessarily those of the NationalHealth Service, the NIHR or the Department of Health.

Competing interests None declared.

Patient consent Not required.

Ethics approval Ethical and regulatory approvals were obtained (Bradford Ethics Committee, part of the Yorkshire and Humber National Research and Ethics Service, ref: $12 / \mathrm{YH} / 0534)$.

Provenance and peer review Not commissioned; externally peer reviewed.

Data sharing statement The data sets used and analysed during the current study are available from the corresponding author on reasonable request.

Open access This is an open access article distributed in accordance with the Creative Commons Attribution Non Commercial (CC BY-NC 4.0) license, which permits others to distribute, remix, adapt, build upon this work non-commercially, and license their derivative works on different terms, provided the original work is properly cited, appropriate credit is given, any changes made indicated, and the use is non-commercial. See: http://creativecommons.org/licenses/by-nc/4.0/.

\section{REFERENCES}

1. Ozdemir BA, Karthikesalingam A, Sinha S, et al. Research activity and the association with mortality. PLoS One 2015;10:e0118253.

2. Lichten CA, Marsden G, Pollitt A, et al. Does a biomedical research centre affect patient care in local hospitals? Health Res Policy Syst 2017;15:2.
3. García-Romero A, Escribano Álvaro, Tribó JA. The impact of health research on length of stay in Spanish public hospitals. Res Policy 2017;46:591-604.

4. Boaz A, Hanney S, Jones T, et al. Does the engagement of clinicians and organisations in research improve healthcare performance: a three-stage review. BMJ Open 2015;5:e009415.

5. American Psychiatric Association. Diagnostic and Statistical Manual of Mental Disorders (DSM-5). 5 edn, 2013.

6. Ryan DJ, O'Regan NA, Caoimh RÓ, et al. Delirium in an adult acute hospital population: predictors, prevalence and detection. BMJ Open 2013;3:e001772.

7. Ely EW, Inouye SK, Bernard GR, et al. Delirium in mechanically ventilated patients: validity and reliability of the confusion assessment method for the intensive care unit (CAM-ICU). JAMA 2001;286:2703-10.

8. Maclullich AM, Anand A, Davis DH, et al. New horizons in the pathogenesis, assessment and management of delirium. Age Ageing 2013;42:667-74

9. Vasilevskis EE, Han JH, Hughes CG, et al. Epidemiology and risk factors for delirium across hospital settings. Best Pract Res Clin Anaesthesiol 2012;26:277-87.

10. Teodorczuk A, Reynish E, Milisen K. Improving recognition of delirium in clinical practice: a call for action. BMC Geriatr 2012;12:55.

11. Laurila JV, Pitkala KH, Strandberg TE, et al. Detection and documentation of dementia and delirium in acute geriatric wards. Gen Hosp Psychiatry 2004;26:31-5.

12. Collins N, Blanchard MR, Tookman A, et al. Detection of delirium in the acute hospital. Age Ageing 2010;39:131-5.

13. Bellelli G, Nobili A, Annoni G, et al. Under-detection of delirium and impact of neurocognitive deficits on in-hospital mortality among acute geriatric and medical wards. Eur J Intern Med 2015;26:696-704.

14. Dramé M, Lang PO, Novella JL, et al. Six-month outcome of elderly people hospitalized via the emergency department: the SAFES cohort. Rev Epidemiol Sante Publique 2012;60:189-96.

15. Heymann A, Radtke F, Schiemann A, et al. Delayed treatment of delirium increases mortality rate in intensive care unit patients. $J$ Int Med Res 2010;38:1584-95.

16. Kakuma R, du Fort GG, Arsenault L, et al. Delirium in older emergency department patients discharged home: effect on survival. J Am Geriatr Soc 2003;51:443-50.

17. Jackson TA, Wilson D, Richardson S, et al. Predicting outcome in older hospital patients with delirium: a systematic literature review. Int J Geriatr Psychiatry 2016;31:392-9.

18. Inouye SK, Westendorp RG, Saczynski JS. Delirium in elderly people. Lancet 2014;383:911-22.

19. Luetz A, Weiss B, Boettcher S, et al. Routine delirium monitoring is independently associated with a reduction of hospital mortality in critically ill surgical patients: A prospective, observational cohort study. J Crit Care 2016;35:168-73.

20. Clegg A, Westby M, Young JB. Under-reporting of delirium in the NHS. Age Ageing 2011;40:283-6.

21. Jenkin RP, Al-Attar A, Richardson S, et al. Increasing delirium skills at the front door: results from a repeated survey on delirium knowledge and attitudes. Age Ageing 2016;45:517-22.

22. Jenkin RP, Musonda P, MacLullich AM, et al. Specialty experience in geriatric medicine is associated with a small increase in knowledge of delirium. Age Ageing 2014;43:141-4.

23. National Insitute for health and Clinical Excellence (NICE). Delirium: prevention, diagnosis and management - Clinical guideline [CG103], 2010.

24. Jackson TA, MacLullich AM, Gladman JR, et al. Diagnostic test accuracy of informant-based tools to diagnose dementia in older hospital patients with delirium: a prospective cohort study. Age Ageing 2016;45:505-11.

25. James Lind Alliance. Priority setting partnerships - dementia top 10. NIHR evaluation, trials and studies coordinating centre, 2013.

26. Meagher DJ, Morandi A, Inouye SK, et al. Concordance between DSM-IV and DSM-5 criteria for delirium diagnosis in a pooled database of 768 prospectively evaluated patients using the delirium rating scale-revised-98. BMC Med 2014;12:164.

27. Fisher JM, Gordon AL, MacLullich AM, et al. Towards an understanding of why undergraduate teaching about delirium does not guarantee gold-standard practice-results from a UK national survey. Age Ageing 2015;44:166-70. 